\title{
Recoverable and Nonrecoverable Deficits in Conditioned Responses after Cerebellar Cortical Lesions
}

\author{
J. A. Harvey, ${ }^{1}$ J. P. Welsh, ${ }^{1, a}$ C. H. Yeo, ${ }^{2}$ and A. G. Romano' \\ 'Division of Behavioral Neurobiology, Department of Pharmacology, The Medical College of Pennsylvania/EPPI, \\ Philadelphia, Pennsylvania 19129 and 'Department of Anatomy and Developmental Biology, Centre for Neuroscience, \\ University College London, London WC1E 7JG, United Kingdom
}

This study reexamined the effects of unilateral damage to cerebellar hemispheral lobule VI on the rabbit's conditioned nictitating membrane (NM) response. Extensive unilateral removal of hemispheral lobule VI in 11 rabbits impaired ipsilateral conditioned responses as reflected by reductions of $52 \%$ in mean frequency and $53 \%$ in mean amplitude during test trials on the first postoperative session. The decreases in the amplitude and frequency of conditioned responses were highly correlated $(r-0.82)$. The frequency of conditioned responses recovered to control levels but their amplitudes remained reduced such that the correlation between these two measures of responding was no longer significant by the 12th postoperative conditioning session. The decrease in the amplitude of conditioned responses was not accompanied by changes in onset latency or rise time. There was no significant impairment of conditioned responses in surgical controls and animals with only partial damage to hemispheral lobule VI. It was concluded that hemispheral lobule VI plays an important role in the regulation of motor centers in the brainstem so as to facilitate the initiation and optimum execution of the conditioned NM reflex. This cortical regulation of the conditioned NM response may contain learned elements; however, these cannot be resolved with lesion methods, nor has their existence been proven in this or other lesion studies. Nevertheless, the results of this study do demonstrate that the cerebellar cortex cannot be considered as the single locus necessary for NM conditioning.

[Key words: cerebellar cortex, hemispheral lobule VI, rabbit, nictitating membrane, classical conditioning, motor function]

Aspiration lesions of hemispheral lobule VI (HVI) and ansiform lobule (ANS) were used by Yeo et al. (1985a) and subsequently by Lavond et al. (1987) to test the involvement of cerebellar cortex in classical conditioning of the nictitating membrane (NM)

\footnotetext{
Received Jan. 3, 1992; revised Oct. 6, 1992; accepted Oct. 14, 1992.

This work was supported by U.S. Public Health Service Grant MH16841-23. We thank S. E. McMaster, N. M. Bormann, and J. Swarts for their excellent technical assistance throughout these studies and P. Reimann of the University of Iowa for photomicrography.

Correspondence should be addressed to John A. Harvey, Ph.D., Chief, Division of Behavioral Neurobiology, Department of Pharmacology, The Medical College of Pennsylvania, 3200 Henry Avenue, Philadelphia, PA 19129.

a Present address: Department of Physiology and Biophysics, New York University Medical Center, 550 First Avenue, New York, NY 10016.

Copyright (C) 1993 Society for Neuroscience $0270-6474 / 93 / 131624-12 \$ 05.00 / 0$
}

response. These cortical areas were initially chosen by Yeo et al. (1985a) because the corneal air puff or periocular electrical pulse unconditioned stimulus (US) used in conditioning activates trigeminal afferents to areas in the inferior olive that project robustly to HVI and ANS (Miles and Wiesendanger, 1975a,b; Cody and Richardson, 1979; Gellman et al., 1983; Yeo et al., $1985 \mathrm{~b}$ ). These cortical areas also receive auditory and visual inputs (Snider and Stowell, 1944), which could lead to a convergence of CS and US and thus provide a locus for associative learning. Yeo et al. (1985a) and Lavond et al. (1987) observed a large postoperative decrement in conditioned responses (CRs) as measured by both their frequency and amplitude but no effect on the UR. Both Yeo et al. (1985a) and Lavond et al. (1987) interpreted the postoperative decreases in CR frequency to reflect a deficit in associative learning and not a performance deficit. However, there was disagrecment as to the duration of this effect. Yeo et al. (1985a) failed to observe any recovery and concluded that the deficits were permanent, while Lavond et al. (1987) reported that animals demonstrated full recovery such that CR frequency and amplitude were no longer significantly different from control values. Subsequently, Lavond and Steinmetz (1989) examined initial acquisition of CRs following extensive removal of HVI and reported that these cortical lesions delayed the acquisition of CRs as measured by their frequency and amplitude but had no effect on the unconditioned response (UR). They concluded that although HVI was not essential for classical conditioning, it normally played an important role in learning through a modulatory influence on the interpositus nucleus, the latter being essential for learning. More recently, Yeo and Hardiman (1992) reported that cortical lesions enhanced the amplitude of URs, raising the possibility that performance variables might indeed be impairing CR production. In addition, Yeo and Hardiman (1992) found that there was a higher frequency of CRs on conditioned stimulus (CS)alone test trials as compared with paired trials, an effect that could be due to the presence of a performance deficit that is, perhaps, related to an impairment in response initiation. However, Yeo and Hardiman (1992) observed that the depression of CR excitation characterized by impaired amplitudes, frequencies, and initiation did not relate in a simple way to the accompanying increase in excitability of the UR. A common performance deficit might not produce these differential excitabilities, and it is possible that CRs were depressed by a learning loss. The recovery of CRs with continued training, particularly by those subjects with subtotal lesions, could be consistent with a learning deficit embedded within general changes of excitability of the NM response. 
We have reexamined the role of the cerebellar cortex in the regulation of CRs to determine the extent to which deficits in $\mathrm{CR}$ frequency and topography after cortical damage were recoverable, as suggested by the studies of Lavond et al. (1987) and Lavond and Steinmetz (1989), or were, at most, only partially recoverable, as suggested by Yeo et al. (1985a) and Yeo and Hardiman (1992). This was accomplished by examining the effects of extensive damage to HVI along with varying amounts of damage to the adjacent ANS on the rabbit's conditioned NM response. In addition, through the use of CS-alone trials, we also examined in greater detail how HVI lesions might affect the topography of CRs. Complete CR topographies, including the determination of peak CR amplitudes, can only be determined on test trials. For example, peak $\mathrm{CR}$ amplitudes are typically reached after the time of US onset and, thus, their measurement is obscured by the occurrence of the UR during paired CS-US trials. The accurate measurement of CR amplitudes during paired CS-US trials may be further compromised in animals with cortical lesions by the increase in UR amplitude reported by Yeo and Hardiman (1992). Finally, animals received 16 days of conditioning preoperatively so that lesion effects on $\mathrm{CR}$ production could be measured from stable, postasymptotic baselines.

\section{Materials and Methods}

Subjects. Rabbits of both sexes (New Zealand white albino), weighing 1.75-2.25 kg on arrival, were obtained from Hazelton Research Animals (Denver, PA). They were housed individually under a $12 \mathrm{hr} / 12 \mathrm{hr}$ light/ dark cycle, and maintained on rabbit chow and water

Apparatus and general procedure. The apparatus, including the IBM PC-AT and ASYST software for stimulus control and data acquisition, have been described in detail (Romano et al., 1991). Briefly, animals were placed in Plexiglas restrainers and fitted with a headmount that supported a potentiometer and a $2-\mathrm{mm}$-diameter metal tube for delivery of the air puff US. The shaft of the low-torque, rotary potentiometer (Litton Potentiometer Division, PS091-023) was directly coupled to a suture placed in the NM. Movements of the NM were transduced to DC voltages and digitized every $5 \mathrm{msec}$ with a resolution of $0.03 \mathrm{~mm}$ of NM movement per analog-to-digital (A/D) count.

Preoperative conditioning procedure. The general methods employed for conditioning of the rabbit's NM response followed those described by Welsh and Harvey (1989b) using the equipment described by Romano et al. (1991). Briefly, each animal was placed in a sound-attenuating chamber illuminated by two $24 \mathrm{~V}, 6 \mathrm{~W}$ lightbulbs positioned on either side of a $7.6 \mathrm{~cm}$ speaker (Boston Acoustics, model 703). Conditioning of the right nictitating membranc was accomplished by pairing a $250 \mathrm{msec}, 84 \mathrm{~dB}, 1 \mathrm{kHz}$ tone delivered through the speaker with a $100 \mathrm{msec}$ air puff US delivered through the metal tube. The tube was positioned $6 \pm 1 \mathrm{~mm}$ from the center of the right cornea, and air puff pressure measured at the end of the tube was $200 \mathrm{gm} / \mathrm{cm}^{2}$. Each daily conditioning session consisted of 66 trials presented with a mean intertrial interval of $60 \mathrm{sec}$ (range, 50-70 sec). The 66 trials were divided into six blocks of 11 trials. Within each block, the first 10 trials consisted of paired presentations of the tone CS and air puff US. The interval between CS and US onsets was $250 \mathrm{msec}$. The 11 th trial in each block was a test trial during which the $250 \mathrm{msec}$ tone CS was presented alone. Thirty-two animals received one $66 \mathrm{~min}$ adaptation session followed by 15 or 16 conditioning sessions preoperatively.

Surgery. Thirty-two rabbits underwent surgery 1 and $5 \mathrm{~d}$ after the last preoperative conditioning scssion using the general procedures described by Yeo et al. (1985a). All rabbits were anesthetized with an intramuscular injection of ketamine hydrochloride $(50 \mathrm{mg} / \mathrm{kg})$ supplemented with acepromazine maleate $(1 \mathrm{mg} / \mathrm{kg})$ and xylazine hydrochloride $(5 \mathrm{mg} / \mathrm{kg}$ ) followed by $50 \mathrm{ml}$ of $20 \%$ (w/v) mannitol intravenously to dehydrate the brain. Animals were then placed in a stereotaxic headholder and maintained under halothane anesthesia administered through a $3.5 \mathrm{~mm}$ pediatric endotracheal tube. The skull overlying the right cerebellar cortex was removed and the underlying dura was cut and reflected to expose the superior surface of the cerebellar cortex. Seven animals received no further surgery and served as surgical controls.
Twenty-five other rabbits received aspiration lesions intended to remove HVI or HVI and the adjacent ANS. After surgery, the cortical surface was covered with sterile absorbable gelatin foam and the scalp was sutured.

Postoperative procedures. Beginning immediately after surgery, and during the next day, all animals received a $50 \mathrm{ml}$ subcutaneous injection of a $5 \%$ dextrose, $0.9 \%$ sodium chloride solution to counteract dehydration produced by mannitol. Animals also received a $1.0 \mathrm{ml}$ intramuscular injection of chloramphenicol sodium succinatc $(100 \mathrm{mg} / \mathrm{ml})$ for $4 \mathrm{~d}$. All animals appeared normal and active on the day following surgery. At 20 or $21 \mathrm{~d}$ following surgery, animals were exposed to 12 additional daily conditioning sessions that were identical to the preoperative procedures. At the end of the study, all animals, including the surgical controls, were injected with a lethal dose of sodium pentobarbital (195 mg, i.v.) and perfused through the heart with $0.9 \%$ saline followed by $10 \%$ formalin. The brains were removed, stored in $30 \%$ sucrose formalin for at least 2 weeks, and embedded in gelatin. Coronal sections, $60 \mu \mathrm{m}$ thick, were obtained at $0.25 \mathrm{~mm}$ intervals throughout the cerebellum and inferior olive and stained with buffered cresyl violet. Based on microscopic examination of the histological material, the extent of each lesion was reconstructed onto a series of transverse plates of the rabbit cerebellum. Evaluation of these lesions was carried out independently by two of the authors (J.P.W. and C.H.Y), ncither of whom were aware of the behavioral findings associated with each animal.

Response definition. The frequency and topography of responses were determined according to the procedures of Welsh and Harvey (1989b) and Romano et al. (1991). A response was defined as at least $0.5 \mathrm{~mm}$ (16 A/D counts) of membrane extension. On paired trials, responses were scored as CRs if they occurred during the $250 \mathrm{msec}$ CS-US interval and as URs if they occurred within $800 \mathrm{msec}$ after US onset. On CSalone trials, responses were scored as CRs if they occurred within 800 msec of CS onset. Once a response was detected, its latency was determined by searching successively earlier A/D samples of the NM waveform to establish when the response first deviated from baseline by at least one A/D count (i.e., $0.03 \mathrm{~mm}$ ). Measures obtained during paired CS-US trials included only the percentage occurrence of CRs and URs and their onset latencies. Analysis of the full topography of the $\mathrm{CR}$ could only be determined during the CS-alone test trials (see Welsh and Harvey, 1989b). CRs occurring during CS-alone trials were characterized in terms of their onset latencies, peak amplitude, latency to peak amplitude, and rise time.

Data analysis. A repeated-measures analysis of variance (ANOVA) using the SYSTAT statistical package (Wilkinson, 1988) was carried out on the various response measures. Follow-up tests of simple main effects were performed with the method of Dunnett to allow comparison of all experimental groups with the surgical controls (Winer, 1971). Significance for all statistical comparisons was set at $p \leq 0.05$.

\section{Results}

\section{Locus of lesions}

The lesions of cerebellar cortex could be divided into two groups. One group of animals (total HVI, $n=11$; T1-T11) had either total or near total ablation of HVI characterized by a very slight sparing of Purkinje cells in the most ventral and medial part of the lobule at the depths of the primary fissure. In most cases there was accompanying extensive damage to the ANS involving Crus I and Crus II. None of the lesions extended into the deep cerebellar nuclei. These lesions were essentially identical with those reported by Yeo and Hardiman (1992). Figures 1 and 2 present photomicrographs taken through the major extent of these lesions for each of the animals (T1-T11). Serial reconstructions are presented for the overall largest lesion in the total HVI group (T1; Fig. 3), an intermediate lesion (T11; Fig. 4), and the smallest lesion (T8; Fig. 4). This overall smallest lesion, T8, was the most complete lesion of HVI and involved little other cortical tissue.

A second group of animals (partial HVI, $n=14$; P1-P14) demonstrated less extensive damage to HVI with varying amounts of damage to the ANS. Figure 4 presents serial recon- 


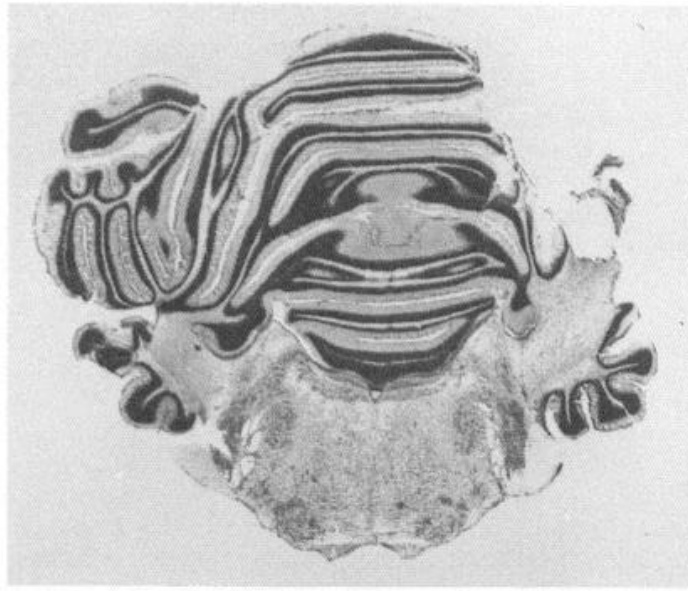

A
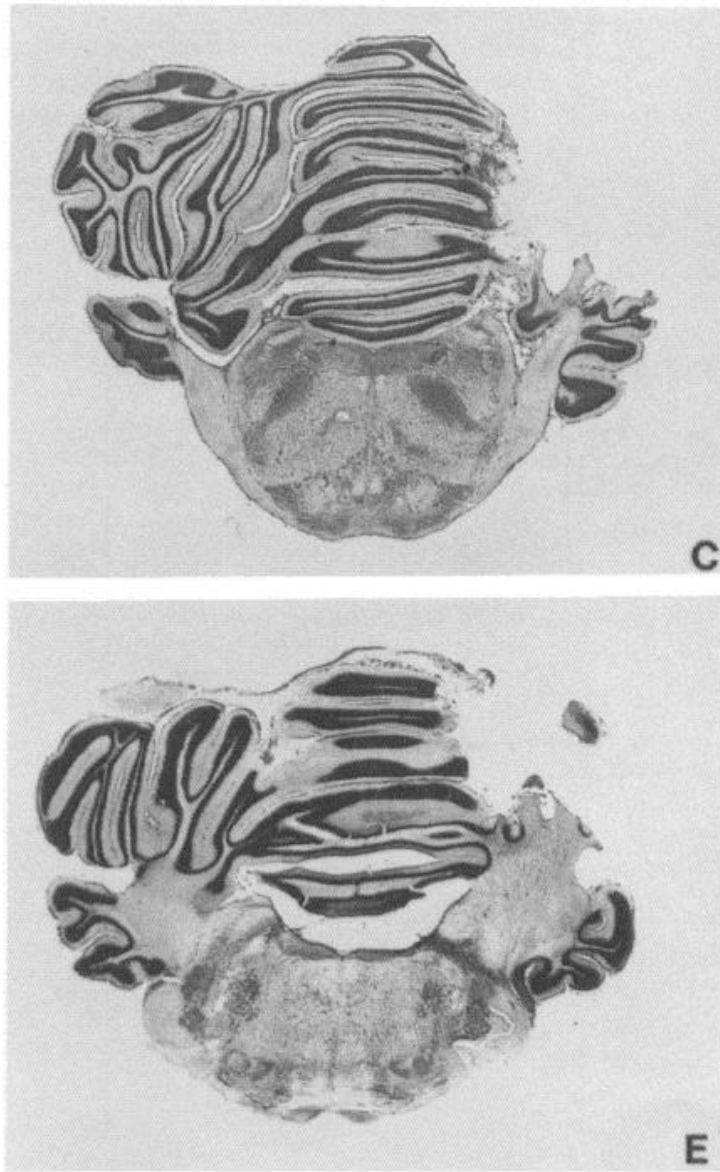

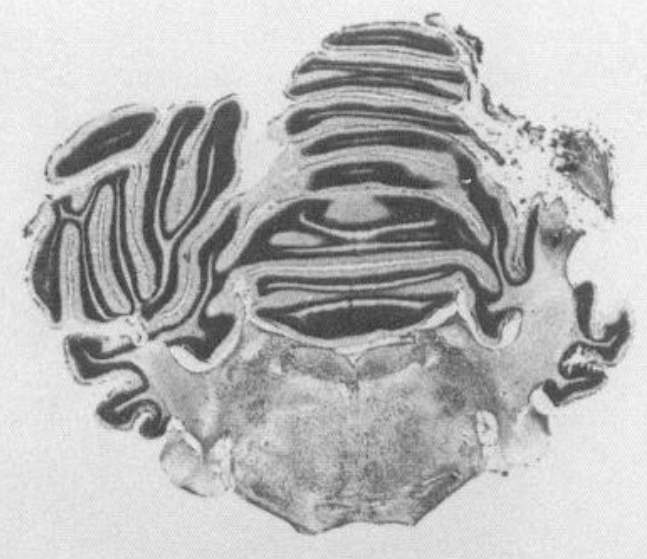

B

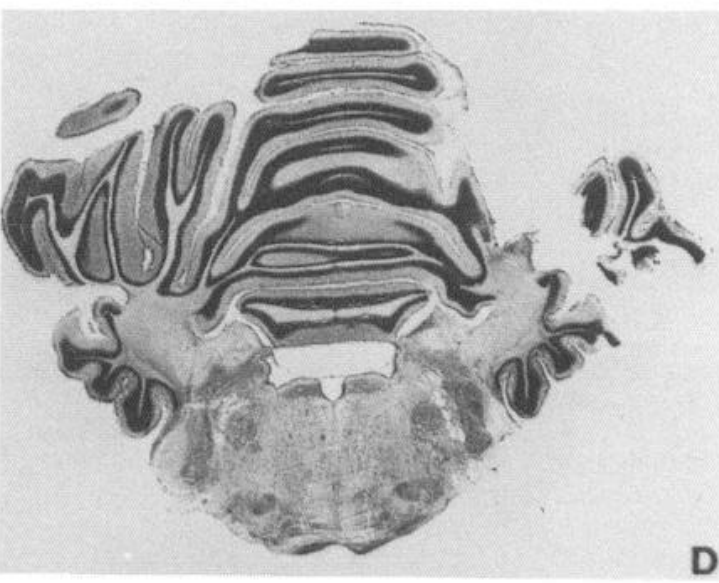

D

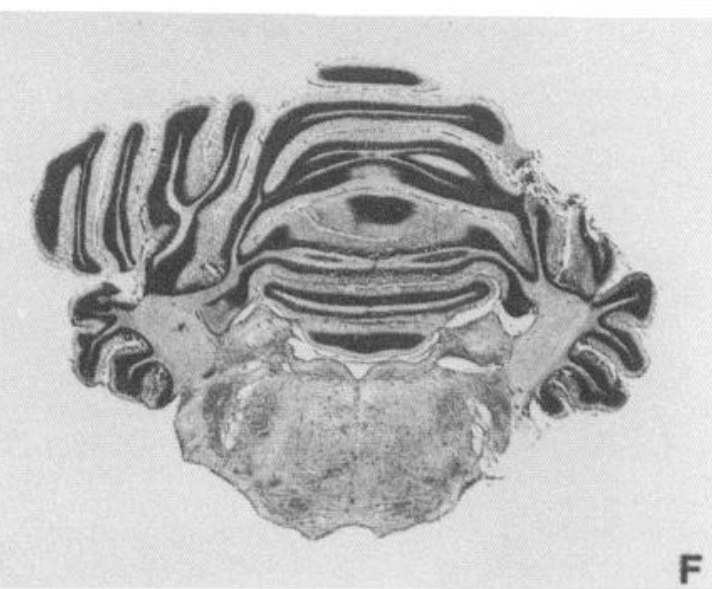

Figure 1. Photomicrographs ( $3 \times$ magnification) taken through the major extent of the aspiration lesions in animals of the total HVI group. Letters refer to animals shown in subsequent figures: $A, \mathrm{~T} 1 ; B, \mathrm{~T} 2 ; C$, T3; $D, \mathrm{~T} 4 ; E$, T5; and $F$, T6.

structions of the largest lesion in the partial HVI group (P2) and a lesion of intermediate size (P4). A third group of animals consisted of surgical controls $(n=7 ; \mathrm{C} 1-\mathrm{C} 7)$. Subsequent analysis of the behavioral effects of cerebellar damage was based on a comparison of the three groups of animals described above: surgical controls $(n=7)$, partial HVI lesions $(n=14)$, and total HVI lesions $(n=11)$. Some animals in the total HVI group and in the partial HVI group exhibited gliotic reactions that extended ventrally from the sites of cortical damage through the white matter and into the deep cerebellar nuclei (dentate, interpositus, and/or fastigial). The increased gliosis occurred either in the interpositus nucleus alone (T11), interpositus plus dentate ( $T 3$, $\mathrm{T} 7, \mathrm{P} 11)$, interpositus plus fastigial (P10, P12), interpositus plus dentate and fastigial (P1, P2), or dentate alone (P7). The increased gliosis occurred in small portions of these nuclei from the level of plates -3.0 to -4.0 of Figure 3 with no evidence of neuronal degeneration (see Fig. 5).

\section{Preoperative acquisition of $C R s$}

All animals demonstrated robust acquisition of CRs across the preoperative conditioning sessions as measured by CR frequency (Fig. 6A), CR onset latency (Fig. 6B), or CR amplitude 

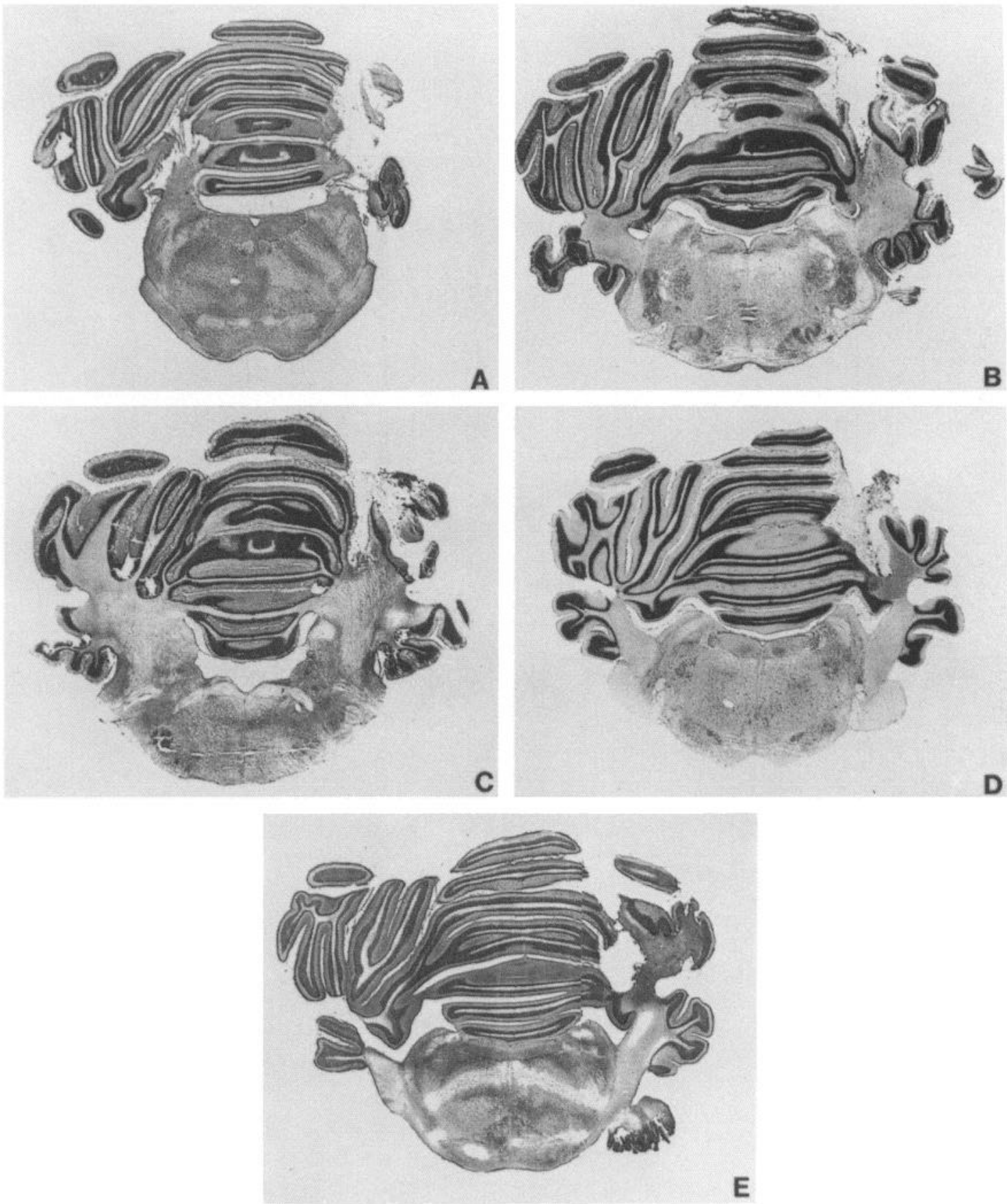

Figure 2. Photomicrographs ( $3 \times$ magnification) taken through the major extent of lesions in animals of the total HVI group. Letters refer to animals shown in subsequent figures: $A, \mathrm{~T} 7 ; B, \mathrm{~T} 8 ; C$, T9; $D$, T10; and $E$, T11.

(Fig. 6C). All three measures had reached postasymptotic levels of performance by the last three preoperative sessions. In agreement with previous findings (Welsh and Harvey, 1989b), a significantly $(p<0.01)$ greater frequency of CRs could be detected on test trials as compared with paired trials during the first $3 \mathrm{~d}$ of conditioning (Fig. $6 \mathrm{~A}$ ). More importantly, there were no preoperative differences among the three experimental groups either in the rate of CR acquisition or in the final performance of CRs as measured by their frequency, amplitude, onset latency, latency of peak amplitude, and rise time (Table 1). These preoperative measures of the postasymptotic performance of CRs were equivalent to those obtained in a previous study employing similar methodologies (Welsh and Harvey, 1989b).

\section{Postoperative deficits in CR performance}

Surgical controls and animals in the partial HVI group failed to demonstrate any significant decreases in mean CR frequency during postoperative testing (Fig. $6 D$ ). However, animals in the total HVI group demonstrated a significant $(p<0.001)$ reduction in the mean percentage of CRs on the first postoperative session whether measured during paired or test trials (Fig. $6 D$, Table 1). Thus, during test trials, animals in the total HVI group 
Figure 3. Serial reconstruction of the lesion sustained by animal $\mathrm{T} l$ of the total HVI group using the transverse sections of Yeo and Hardiman (1992). The plates are numbered from $1 \mathrm{~mm}$ in front of lambda $(+1)$ to $6 \mathrm{~mm}$ posterior to lambda $(-6)$. This was the largest lesion in this study. Abbreviations on the plates relevant to this study are: $c r I$ and $c r I I, C r u s I$ and Crus II (ansiform lobe); $D P F L$, dorsaal paraflocculus; $F L$, flocculus; $N D$, dentate nucleus; $N F$, fastigial nucleus; $N I$, interpositus nucleus; $P M$, paramedian lobe; $H V I$, hemispheral lobule HVI; $I I-$ $V I$, vermian lobules II-VI.
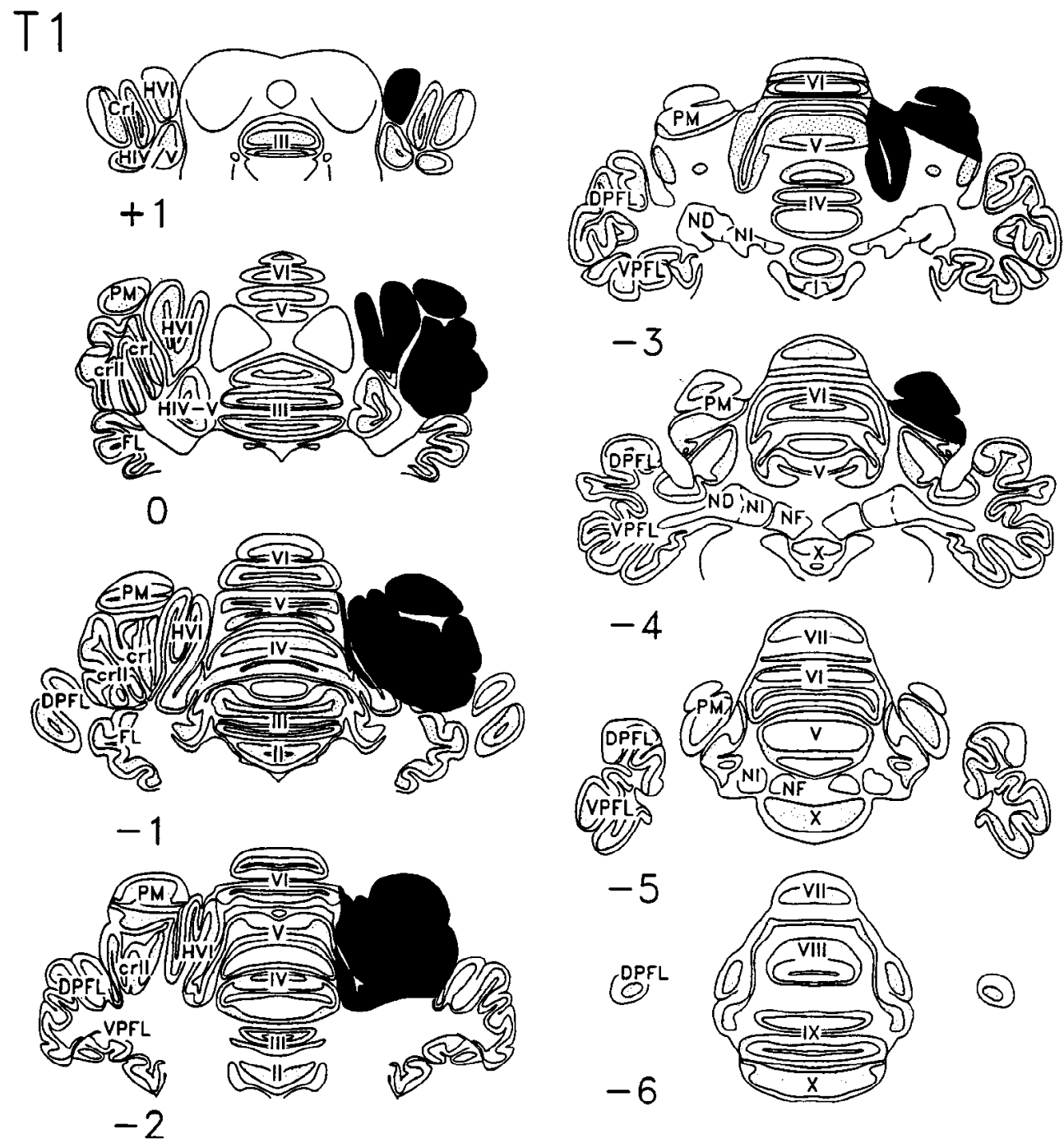

(2) responded to the CS on $45.9 \pm 10.6 \%$ of trials during the first postoperative session as compared with $94.8 \pm 3.4 \%$ for surgical controls and $86.4 \pm 7.3 \%$ for the partial HVI group. It should be noted that all animals, including those exhibiting large decreases in CR frequency, always demonstrated a UR to the US on paired trials.

There was a gradual recovery of CRs over the 12 postoperative sessions with a significantly $(p<0.05)$ greater number of CRs being detected during test as compared with paired trials (Fig. $6 D$ ). The mean percentage of CRs of the total HVI group was no longer significantly different from that of the surgical controls by the last eight conditioning sessions when measured during test trials and by the last three sessions during paired trials. The effects of total HVI lesions on CR frequency were not associated with a significant effect on the onset latency of CRs (Fig. 6E), latency of peak CR amplitude, or CR rise time (Table 1). Nevertheless, it should be noted that the mean onset latencies of the total HVI group were consistently longer than those of animals in the control and partial HVI group (Fig. 6E), and these increases in onset latencies were consistent with the increased frequency of CRs during test as compared with paired trials (see Fig. 6D).

In contrast with the transient effects of cerebellar damage on
CR frequency, animals in the total HVI group demonstrated a large and persistent decrease in CR amplitude (Fig. 6F, Table 1). The mean CR amplitudes of the total HVI group were significantly $(p<0.01)$ reduced when compared with their preoperative values or with the mean of the control and partial HVI groups across all 12 postoperative sessions. In addition, there was no significant change in mean CR amplitudes of the total HVI group across sessions, indicating the absence of any recovery. The postoperative decrease in CR amplitudes was observed in each animal of the total HVI group. For example, the decreases ranged from $15 \%$ to $83 \%$ when expressed as a percentage change in the mean CR amplitude of each animal (calculated across all 12 postoperative sessions) from their preoperative baselines.

On the first postoperative session, animals in the total HVI group demonstrated equivalent decreases in both CR frequency (52\%) and CR amplitude (53\%) from their preoperative baselines. To examine further the relationship between these two measures of CRs, we obtained for each animal the percentage change in CR amplitude and CR frequency calculated separately for postoperative day 1 and day 12 . We then determined the Pearson product-moment correlation coefficient between these two measures. There was a significant $(p<0.01)$ correlation of 

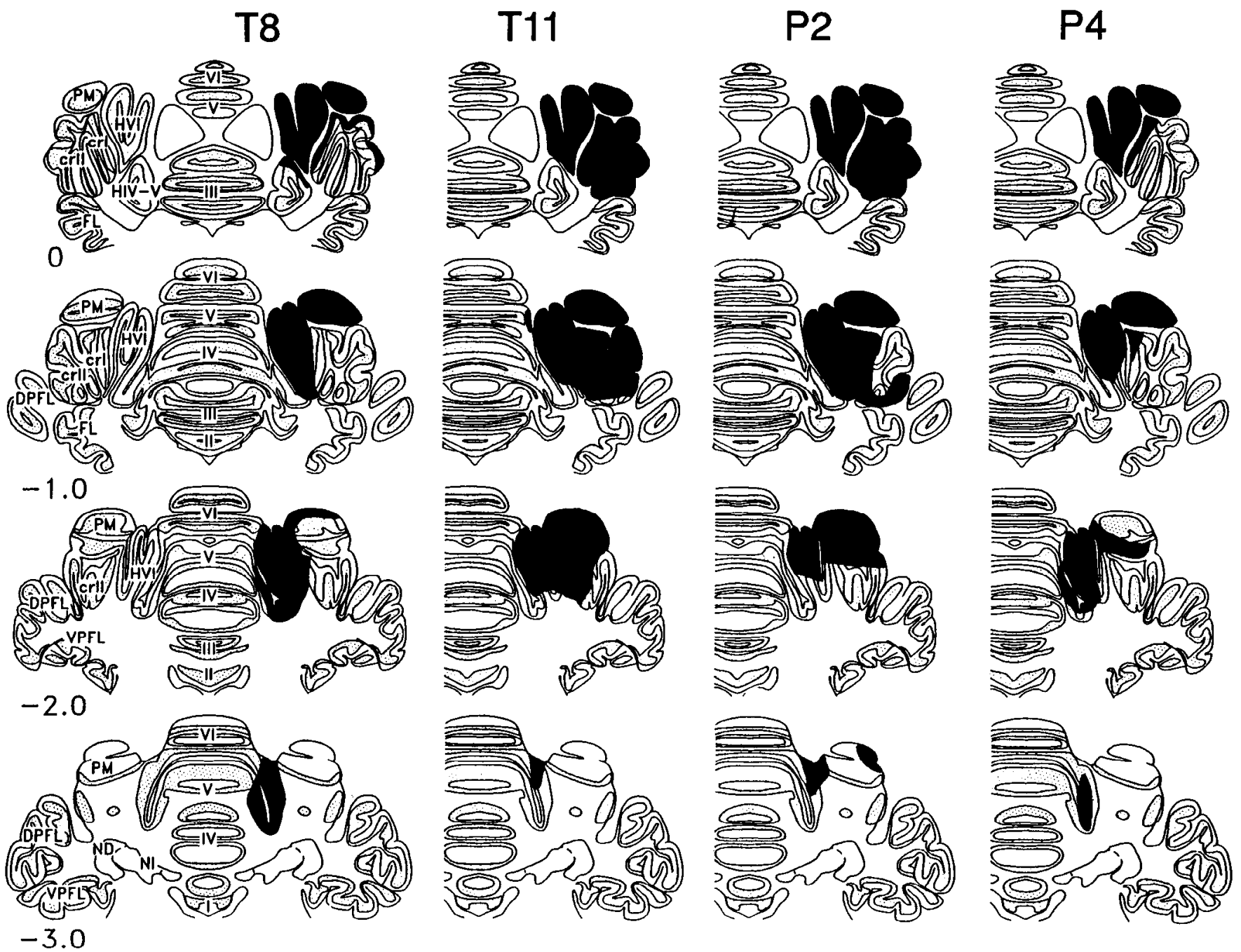

Figure 4. Serial reconstructions of the lesions sustained by animals T8 and T11 of the total HVI group and by animals P2 and P4 of the partial HVI group. Abbreviations are as in Figurc 3.

0.82 between the percentage change in $\mathrm{CR}$ frequency and amplitude on day 1 , but by day 12 the correlation had decreased to 0.36 and was no longer significant.

\section{Relationship of cerebellar damage to CR deficits}

Figure 7 presents the percentage of CRs on paired trials prior to surgery (point above $\mathrm{P}$ ) and across the 12 postoperative sessions for each animal in this study. As can be seen, the seven surgical controls (C1-C7, top left panel) showed no deficits in CRs as compared with their preoperative scores. In the partial HVI group, 10 animals demonstrated greater than $80 \%$ frequency of CRs and four animals (P1, P4, P11, and P13) showed deficits in CR frequency followed by recovery (top right panel). Animals in the total HVI group demonstrated three behavioral effects. Two animals (T5 and T7, bottom left panel) showed little postoperative deficits in percentage of CRs. Two other animals (T3 and T11, bottom left panel) demonstrated a persistent impairment in their ability to perform CRs, which was also characterized by large day-to-day variability. Finally, seven animals (bottom right panel) showed large deficits in CRs on the first postoperative session followed by complete recovery.

The differences in the effects of HVI lesions on CR frequency that were obtained in animals of the total HVI lesion group did not appear to be related to an extension of these lesions into more lateral areas of the cerebellum or into the deep cerebellar nuclei. For example, animal T1 had the greatest amount of damage to lateral cerebellar tissue (see Figs. 1A, 3). As can be seen in Figure 3, this lesion removed all but the most ventral part of HVI and also destroyed more than $90 \%$ of the ANS, with only the most lateral aspects of the posterior portion of the ANS (Crus II) being spared. In addition, a large extent of the paramedian lobule was removed. Although animal T1 did demonstrate a decrease in CRs postoperatively (Fig. 7, bottom right panel), the effects of this lesion were far less than those produced by the overall smallest lesion in this group (animal T8). In animal T8, there was a total ablation of HVI (greater than that of animal T1) but with little involvement of other cerebellar structures and no evidence of gliosis in any of the deep cerebellar nuclei (see Figs. $2 B$, 4). Animal T8 demonstrated a greater postoperative deficit in CRs and a longer recovery period than animal T1 (Fig. 7, bottom right panel). Finally, an animal that demonstrated a persistent impairment characterized by large day-to-day variability in percentage of CRs (T11, Fig. 7 , bottom left panel) had an intermediate-sized lesion involving 

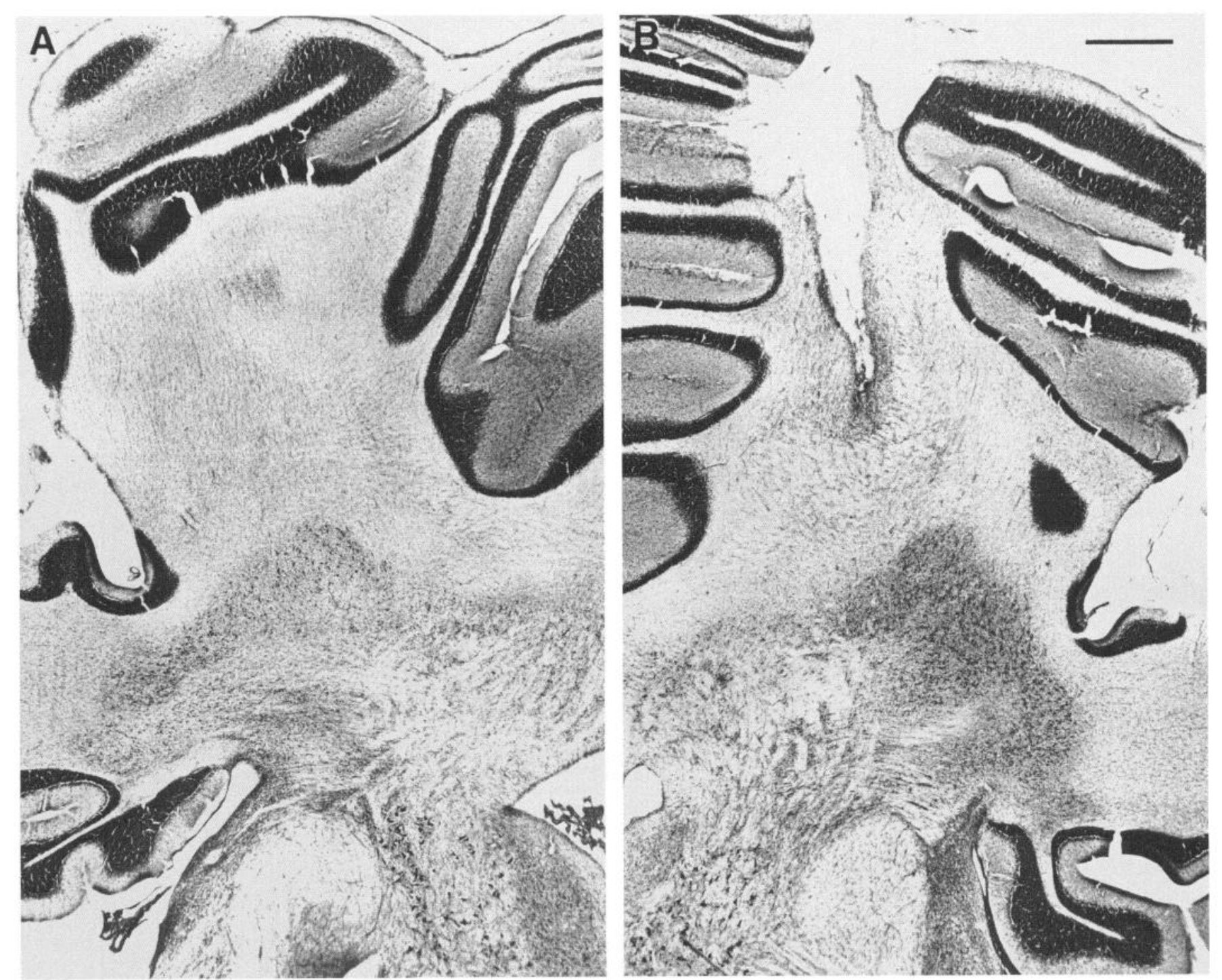

Figure 5. Photomicrographs of the left $(A)$ and right $(B)$ hemicerebellum of animal T7. Note the wedge-shaped lesion in $B$, which has selectively removed the most posterior HVI. Heavy gliosis can be seen in the right dorsolateral interpositus and dorsal dentate immediately ventral to the lesion in $B$. Neurons of normal size can be seen within the field of gliosis in the right deep cerebellar nuclei of $B$. Note also the normal appearance of neurons and the absence of gliosis in the contralateral, left, deep nuclei of $A$. Scale bar, $1 \mathrm{~mm}$.

all of HVI but only the most medial portions of the ANS and paramedian lobules (Figs. 2E, 4).

The permanent deficit in mean CR amplitude demonstrated by all animals in the total HVI group also appeared to be due to damage to HVI and not due to additional damage to more lateral cerebellar cortex. For example, both animal T1 with the largest overall lesion and animal T8 with a lesion restricted predominantly to HVI demonstrated comparable decreases in CR amplitude of $40 \%$ and $60 \%$, respectively.

None of the lesions extended ventrally into the deep cerebellar nuclei. As noted above, some animals demonstrated an increased number of glial cells in the ipsilateral dentate, interpositus, and/or fastigial nuclei with no evidence of any neuronal cell loss (see Fig. 5). However, there was no relationship between the presence, locus, or extent of such gliosis and deficits in CR performance in the total HVI or partial HVI groups. For example, there was increased gliosis in the interpositus nucleus of two animals (T3 and T11) that demonstrated persistent impairments in both the frequency and amplitude of CRs (Fig. 7), but an equivalent amount of gliosis within the interpositus nucleus was also present in animals showing little or no CR deficits (T7, P1, P2, P10, P11, and P12).

\section{Discussion}

\section{HVI modulates $C R$ performance}

The results of this study indicate that HVI is required for optimal performance of the conditioned NM reflex. The initial effect of HVI lesions was to produce an equivalent and highly correlated decrease in CR frequency and amplitude. These effects occurred in the absence of any significant changes in the temporal characteristics of the CR such as onset latency or rise time and in no case was there an abolition of CRs. The decrease in CR frequency was quite variable with two animals showing little change, seven animals showing CR deficits with subsequent recovery, and two animals showing deficits with no recovery. By contrast, HVI lesions produced a consistent and apparently nonrecoverable decrease in $\mathrm{CR}$ amplitude. The decrease in CR amplitude was due to the loss of HVI since it (1) occurred only 

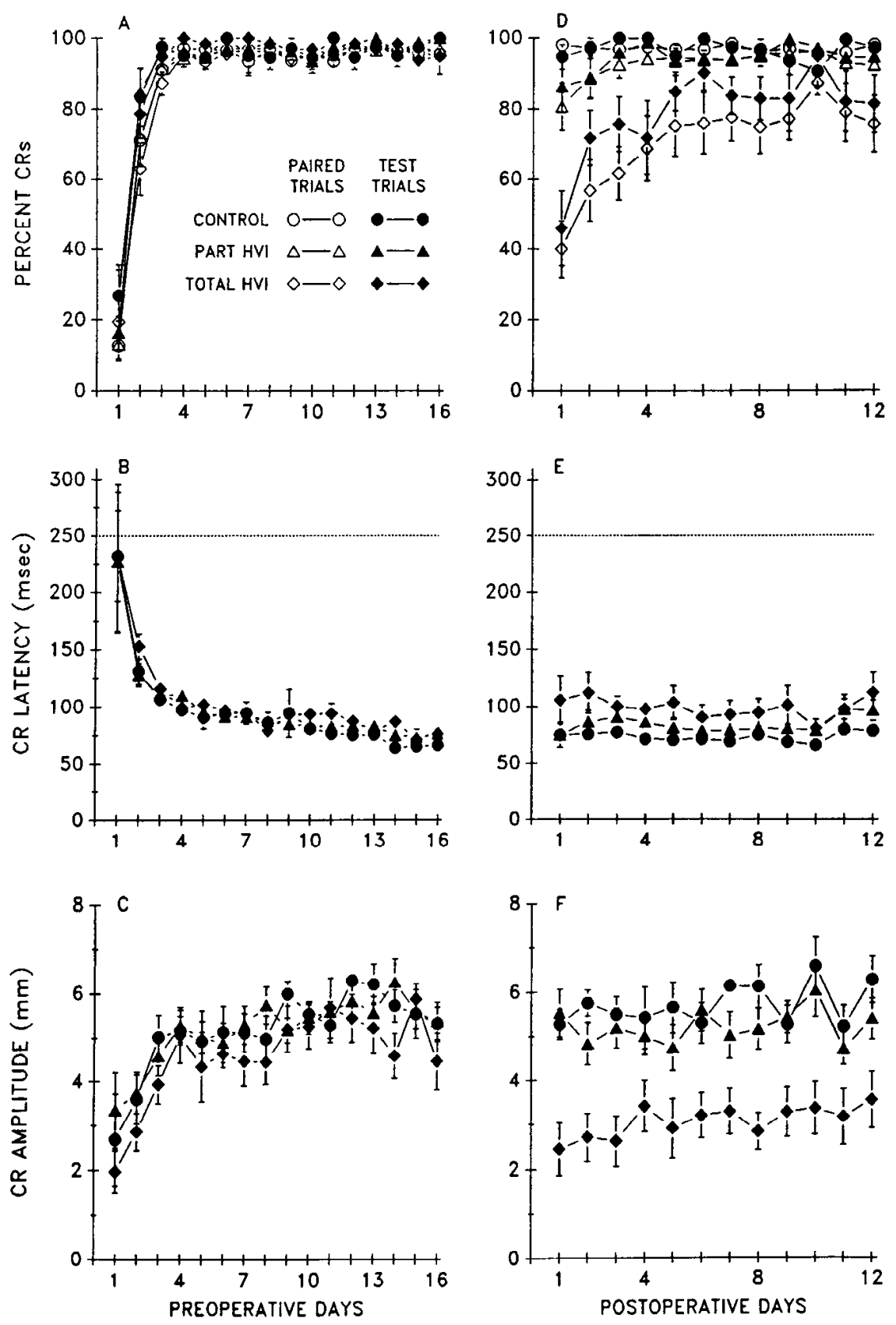
Figure 6. Preoperative acquisition (A- $C)$ and postoperative performance $(D-$ $F)$ of CRs as measured by their fre- quency $(A$ and $D)$, onset latency $(B$ and $E)$, and amplitude $(C$ and $F)$. Open symbols indicate $C R$ measurements ob- tained during the 60 daily paired trials, and solid symbols, during the six daily test trials. Error bars indicate SEM. In some cases the error bars are not visible because the SE was less than the di- ameter of the symbol.

in animals of the total HVI group, (2) was not related to any additional damage to surrounding cortical tissue, and (3) was not related to any damage to the interpositus nucleus. The permanent impairment in CR amplitude obtained in this study occurred despite extensive preoperative training. It should be noted that all previous measurements of CR extension after cerebellar cortical lesions in the rabbit (Yeo et al., 1985a; Lavond et al., 1987; Lavond and Steinmetz, 1989; Yeo and Hardiman, 1992) actually employed measures of CR magnitude and not amplitude (see Gormezano, 1966). The measure of CR magnitude was based on the maximum extent of NM movement within the CS-US interval (on paired trials) or during and immediately after CS presentation (on unpaired trials). This peak extension, whether it is less than or greater than the criterion amplitude defined for the estimation of CR frequency, contributes to the expression of $\mathrm{CR}$ magnitude. In contrast, mean CR amplitude is derived only from NM extensions that exceed the amplitude criterion that defines the occurrence of a response. So, for example, a lesioned subject that produced 15 CRs of $5 \mathrm{~mm}$ amplitude and 85 "responses" smaller than the $0.5 \mathrm{~mm}$ criterion would have a mean CR amplitude of $5 \mathrm{~mm}$ but a mean CR magnitude that could be well below $1 \mathrm{~mm}$. Thus, as the percentage of CRs approaches 100, the measure of CR magnitude approaches the measure of CR amplitude, but as the percentage of CRs decreases, the measure of mean CR magnitude becomes significantly smaller than that of mean CR amplitude.

\section{$C K S$ and URs are differentially regulated by HVI}

The effects of HVI lesions on the CR were different from those on the UR. In agreement with previous studies (Yeo et al., 1985a; Lavond et al., 1987), the frequency of URs elicited by 
Table 1. CR characteristics on test trials

\begin{tabular}{lccc} 
CR measure & $\begin{array}{l}\text { Control } \\
(N=7)\end{array}$ & $\begin{array}{l}\text { Partial HVI } \\
(N=14)\end{array}$ & $\begin{array}{l}\text { Total HVI } \\
(N=11)\end{array}$ \\
\hline $\begin{array}{l}\text { Percentage of CRs } \\
\text { Preop-last block }\end{array}$ & $97.6 \pm 1.1$ & $98.3 \pm 1.0$ & $96.4 \pm 1.4$ \\
$\begin{array}{l}\text { Postop-first block } \\
\text { Postop-last block }\end{array}$ & $97.3 \pm 1.3$ & $90.4 \pm 4.1$ & $64.5 \pm 6.3^{*}$ \\
Amplitude of CRs (mm) & $96.3 \pm 1.9$ & $96.0 \pm 1.3$ & $86.6 \pm 5.7$ \\
Preop-last block & $5.5 \pm 0.4$ & $5.7 \pm 0.4$ & $5.2 \pm 0.3$ \\
Postop-first block & $5.5 \pm 0.2$ & $5.1 \pm 0.5$ & $2.6 \pm 0.4^{*}$ \\
Postop-last block & $6.0 \pm 0.5$ & $5.4 \pm 0.4$ & $3.4 \pm 0.5^{*}$ \\
Onset latency of CRs (msec) & & & $80 \pm 7$ \\
Preop-last block & $65 \pm 3$ & $75 \pm 3$ & $110 \pm 14$ \\
Postop-first block & $76 \pm 4$ & $87 \pm 9$ & $97 \pm 10$ \\
Postop-last block & $75 \pm 3$ & $91 \pm 8$ & $262 \pm 14$ \\
Latcncy of pcak CR amplitude (mscc) & & $301 \pm 30$ \\
Preop-last block & $256 \pm 11$ & $255 \pm 8$ & $266 \pm 24$ \\
Postop-first block & $238 \pm 8$ & $240 \pm 12$ & $182 \pm 11$ \\
Postop-last block & $261 \pm 14$ & $276 \pm 12$ & $190 \pm 25$ \\
Rise time of CRs (msec) & $190 \pm 12$ & $180 \pm 9$ & $169 \pm 17$ \\
Preop-last block & $162 \pm 7$ & $153 \pm 6$ & $186 \pm 11$ \\
Postop-first block & $186 \pm 13$ & & \\
Postop-last block & & & \\
Vosto & & & \\
\hline
\end{tabular}

Values are means \pm SEM for five measures of conditioned responding on tone-alone test trials before (Preop) and after (Postop) surgery. Values are given for Preop-last block, the mean of the last 3 preopcrative days (scssions 14-16); Postop-first block, the mean of the first 3 postoperative days (sessions 1-3); and Postop-last block, the mean of the last 3 postoperative days (sessions 10-12).

${ }^{*} p<0.01$ as compared with preoperative score or with surgical controls.

the suprathreshold US normally used for conditioning was not reduced following the removal of HVI. However, using USalone trials and a range of US intensities, Yeo and Hardiman (1992) found that the amplitude of the UR was enhanced after HVI lesions, a clear demonstration that the cerebellar cortex regulates the motor systems of the unconditioned NM reflex. It is well known that the cerebellar cortex can modulate the threshold of motor systems and that this modulation can be expressed through a facilitation (Snider and Magoun, 1949) or suppression (Snider et al., 1949) of both cerebral and brainstem circuits. The impaired performance of CRs and the enhanced performance of URs after HVI lesions suggest that the cerebellar cortex normally facilitates the brainstem pathways of the CR but normally suppresses the brainstem pathways of the UR. This could be due either to a difference in how the CS and US engage the ccrcbcllar circuitry or to a difference in the projections of the cerebellum to the conditioned as compared with the unconditioned NM pathways.

The influence of the cerebellar cortex upon the NM reflex occurs via the projections of Purkinje cells in HVI to the interpositus nucleus (Yeo et al., 1985b). This projection is exclusively inhibitory (Ito et al., 1964) and produces a phasic decrease in the excitation generated by projections directly upon the interpositus that originate in the brainstem (MacKay and Murphy, 1973, 1974; Llinás and Mühlethaler, 1988). The interpositus, in turn, innervates brainstem motor systems (cf. Jansen, 1969). Auditory stimuli enter the cerebellum through mossy fiber projections that originate in the pontine nuclei (Aitkin and Boyd, 1978), and produce excitation of vermian and paravermian Purkinje cells (Snider and Stowell, 1944). Auditory stimuli also produce an excitation of cells in the deep cerebellar nuclei (Chap- man et al., 1986; Berthier and Moore, 1990) as a result of the projection of mossy fiber collaterals from the pontine nuclei to the deep cerebellar nuclei (Dietrichs et al., 1983; Brodal et al., 1986; Shinoda et al., 1992). Thus, the auditory CS used in the present study could be expected to excite cellular elements of both cerebellar cortex and the interpositus nucleus. Similarly, corneal stimulation, such as that produced by the air puff US, engages the cerebellar circuitry at both the deep nuclear and cortical levels, through the recruitment of climbing fibers originating in the inferior olive (Matsushita and Ikeda, 1970; Berkley and Hand, 1978; Huerta et al., 1983) and mossy fibers originating in the spinal trigeminal nucleus (Somana et al., 1980; Huerta et al., 1983). Therefore, the output of the interpositus, and thus the entire intermediate cerebellum, following an auditory CS or corneal air puff US is determined by an interaction of excitation, mediated via direct mossy and climbing fiber projections to interpositus, and inhibition, mediated via indirect pathways through HVI. Such an interaction has been clearly demonstrated to occur following proprioceptive stimuli (MacKay and Murphy, 1973, 1974). As proposed by Yeo and Hardiman (1992), the fact that removal of HVI facilitates the ability of the US to elicit URs is consistent with an increased excitation within interpositus. This is most likely due to the removal of the inhibitory influence of the descending Purkinje cell projections. Although such an increased excitation in interpositus can explain the increase in UR amplitudes after cortical lesions, it cannot account for the decrease in CR amplitude.

The effects of cortical lesions on CRs and URs differ in several respects from the effects produced by lesions of the interpositus nucleus. Using procedures identical with those employed in this study, Welsh and Harvey (1989b) demonstrated that lesions of 


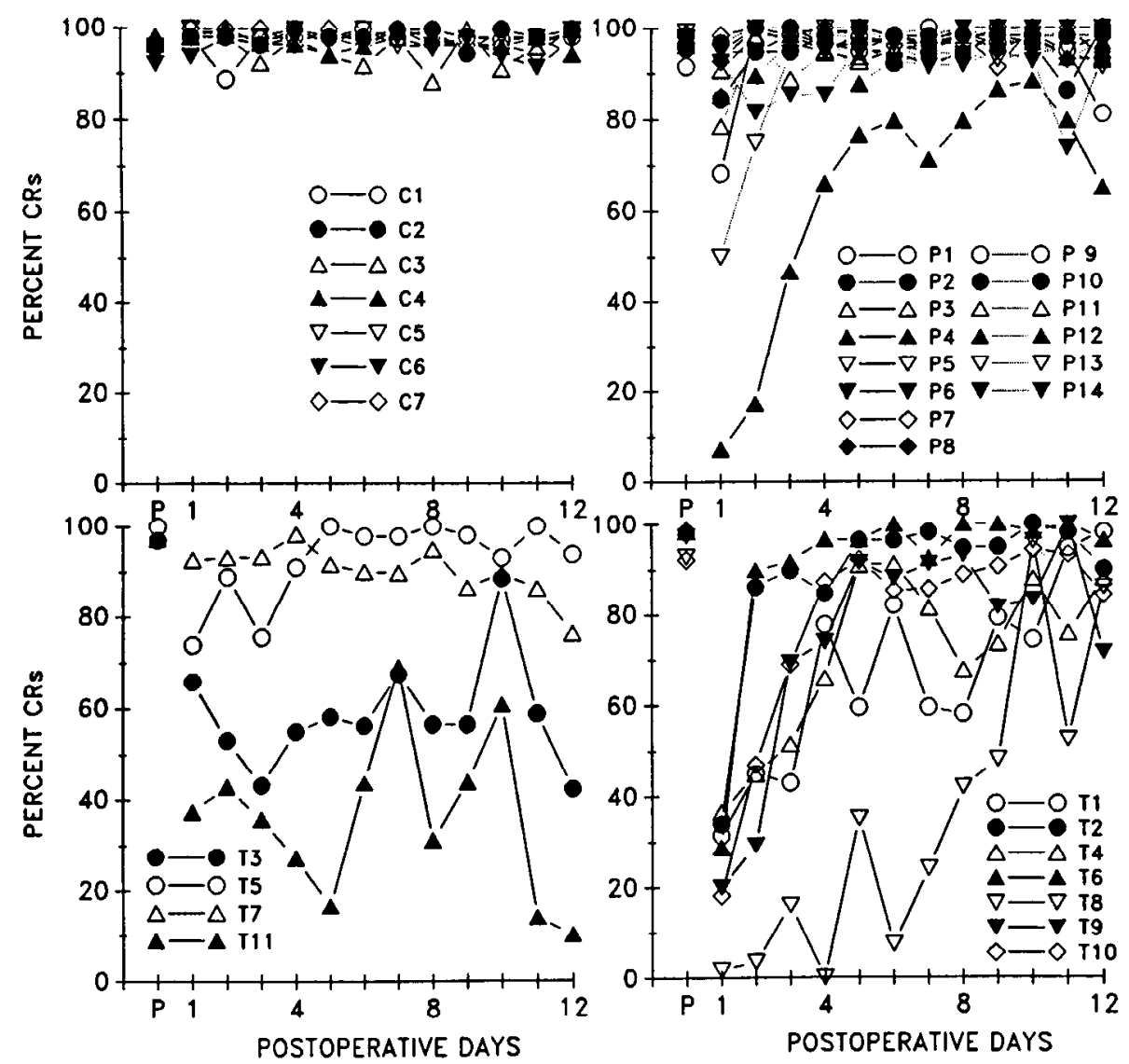

Figure 7. Postoperative frequency of CRs during paired trials for all animals in this study. Surgical controls, upper left; partial HVI group, upper right; and total HVI group, both lower panels. Points above $P$ are the mean percentage of CRs on the last 3 preoperative days (sessions 14-16). interpositus reduced CR amplitude and increased the onset latency, latency of peak amplitude, and rise time of CRs, while cortical lesions in the present study reduced $\mathrm{CR}$ amplitude but did not change the temporal characteristics of the CR. Thus, both HVI and interpositus lesions affect $C R$ amplitude while only interpositus lesions affect the temporal characteristics of the CR (see also Welsh, 1992). The greater degradation of CRs following interpositus as compared with HVI lesions might be due to the additional withdrawal of tonic influences that normally maintain background excitation for motor systems (Dow and Morruzzi, 1958). As a corollary, the reason why HVI lesions reduce only $C R$ amplitudes may be due to the presence of a sufficient amount of regulation of brainstem circuits by the interpositus nucleus so as to allow for normal response topographies. Interpositus lesions also increased the stimulus threshold for URs, reduced their amplitude (Welsh and Harvey, 1989a), and degraded the temporal characteristics of the UR (Welsh and Harvey, 1989a,b; Welsh, 1992) while cortical lesions reduced the stimulus threshold for URs and increased UR amplitude (Yeo and Hardiman, 1992). The sluggishness of URs following interpositus lesions would also be consistent with the removal of deep nuclear regulation of motor circuits in the brainstem.

\section{Is cerebellar circuitry involved in associative learning?}

We have argued that lesions of the cerebellar cortex change the excitability of the NM motor system and that these changes influence both conditioned and unconditioned NM responses. But a fundamental question remains: do general changes in sensory-motor excitability alone account for deficits in CRs or are there also deficits in associative learning? We present two interpretations. One interpretation, that cerebellar cortical lesions produce deficits that are restricted to the performance of the CR, is favored by some of us (J.A.H., J.P.W., A.G.R.). The other interpretation, advanced by one of us (C.H.Y), is that learning deficits may be embedded within changes in performance. The key difference between these interpretations is that the former argues against learning mechanisms in the cerebellar cortex and the latter supports them.

Evidence suggesting that cerebellar circuitry is not involved in associative learning. The significant recovery of CR frequency in the presence of a continued decrement in CR amplitude suggests that removal of HVI had not affected learning, but rather had produced a permanent performance deficit. This deficit was most likely due to an increase in the threshold of brainstem motor systems subserving the NM reflex so as to decrease the ability of the CS to elicit CRs of normal amplitude (Snider and Magoun, 1949). It should be recalled that, before learning, the tone $\mathrm{CS}$ is a subliminal stimulus in that it is capable of activating the motor systems of the NM reflex but not to the extent of eliciting an overt response (Harvey et al., 1985; Harvey, 1987). Classical conditioning of the NM reflex leads to an increase in the excitatory effects of the CS such that it can elicit an NM response (Guegan and Horcholle-Bossavit, 1981; Harvey et al., 1984; Holstege et al., 1986). However, even after considerable conditioning, the CS remains a weaker stimulus with respect to activation of the NM reflex than the suprathreshold US used during conditioning (Welsh and Harvey, 1989a; Welsh, 1992). Therefore, the recovery of CR frequency in subjects with complete removal of HVI could be due to the CS accruing additional associative strength during the 12 postoperative conditioning 
sessions. In this regard, it has been suggested that the underlying neural substrate of the CR comprises two components, the longer latency of which is responsible for at least $30 \%$ of the normal amplitude and is selectively impaired by the interruption of afferents of the cerebellar cortex (Welsh, 1992). That HVI lesions reduced CR amplitude by $42 \%$ suggests an impairment in this long-latency component of the CR. A learning-related increase in the excitatory properties of the CS following HVI lesions may allow a normal frequency of CRs to be expressed through a system that is constrained to a maximal output of only $70 \%$ of normal.

Although the results of this study argue that HVI is not involved in the postoperative acquisition of CRs, some investigators have suggested that $\mathrm{CR}$ acquisition after cortical lesions implicates the interpositus nucleus as a sitc of lcarning (McCormick et al., 1981; McCormick and Thompson, 1984; Lavond et al., 1987; Thompson, 1989). However, using CS-alone test trials, Welsh and Harvey (1989b) found a significant frequency of CRs after unilateral interpositus lesions, and an impairment of the unconditioned NM response on US-alone trials (Welsh and Harvey, 1989a,b; Welsh, 1992). It was suggested that lesions of the interpositus nucleus produce a performance rather than learning deficit (Welsh and Harvey, 1989a,b). In addition, Kelly et al. (1990) reported that cerebellectomy did not impair acquisition of the conditioned NM response in the decerebrate rabbit. Steinmetz et al. (1992) have recently published a rebuttal of the findings of Welsh and Harvey (1989b) in which they reaffirm their belief that the interpositus nucleus is the site of learning for the rabbit's NM response. In the final analysis, the question as to whether interpositus lesions are altering CR frequencics and amplitudes by affecting lcarning or performance (or both) cannot be resolved by the use of irreversible lesions. For this reason, Welsh and Harvey (1991) employed reversible inactivation of the interpositus to resolve these issues. They found that animals failed to demonstrate any evidence of $\mathrm{CR}$ acquisition during inactivation of the interpositus produced by the intracerebellar infusion of lidocaine. However, 2 d later, when the effects of lidocaine had worn off, these animals demonstrated the same frequency of CRs as control animals, indicating that inactivation of the interpositus had blocked the performance but not the acquisition of CRs (Welsh and Harvey, 1991). Taken together, these findings reinforce the longheld view that the cerebellum is necessary for the optimal performance of movements (Luciani, 1915; Holmes, 1917; Brooks, 1986; Welsh and Harvey, 1992) through its regulation of both cerebral and brainstem circuits (Snider and Magoun, 1949; Snider ct al., 1949) and argue against a role for the cercbellum in learning.

Evidence suggesting that cerebellar circuitry is involved in the learning and execution of CRs. That cerebellar cortical lesions produced initial deficits in CR frequency but allowed subsequent recovery is consistent with the suggestion that there is learning within the cerebellar circuitry. The initial deficits are due to the loss of this cerebellar learning and recovery is mediated by increases in associative strength in circuits outside the lesioned area. But because $C R$ amplitudes never recover to preoperative levels, these other circuits cannot support normal CRs. What is the evidence to support this view?

The cerebellar cortex receives auditory mossy fiber inputs that can convey information about the CS. In addition to CS-related mossy fiber inputs, there are US-related mossy and climbing fiber inputs to lobule HVI; there is convergence of CS- and US- related information in lobule HVI. Coactivation of these inputs during conditioning may result in long-term changes in cortical excitability to the $\mathrm{CS}$ that produces the $\mathrm{CR}$ by phasic modulation of the brainstem motor system. Long-term depression of parallel fiber synapses upon Purkinje cells may be the underlying mechanism (Ito, 1989).

In contrast to lesions of the deep nuclei, lesions of the cerebellar cortex enhance UR amplitudes by disinhibition of brainstem sensory-motor circuits (Yeo and Hardiman, 1992). And yet, in the present study, CR frequencies were temporarily impaired and CR amplitudes were permanently reduced despite an apparent increase in reflex excitability. These findings are consistent with the suggestion that the lesions have damaged associative mechanisms within the cerebellar cortex that assist in the generation of CRs.

In other studies, the effects of cerebellar cortical lesions were more severe (Yeo et al., 1985b; Yeo and Hardiman, 1992). Neither the frequencies nor the amplitudes of CRs recovered to preoperative levels, even after 30 postoperative training sessions. The major difference between those studies and the present one relates to the amount of conditioning before the lesions. In the present study, conditioning was very firmly established to postasymptotic levels over 16 preoperative sessions. All studies indicate that CRs can be generated following unilateral cerebellar cortical lesions, but the rate and degree of recovery may be determined by the strength of conditioning before the lesion. Clearly, if learning can also be mediated by circuits outside lobule HVI, then the effects of HVI lesions will be reduced if these circuits have already undergone modifications by extensive training before the lesion, as in the present study.

These findings are consistent with the view that, at an early stage of learning, there are critical associative changes established within the cerebellar cortex. As training continues, associative changes may be established at other sites outside lobule HVI. These additional sites may include additional ipsilateral eye-blink-related cerebellar cortical regions such as those in the flocculus (Nagao et al., 1984), contralateral cerebellar cortical areas, or brainstem sites (Harvey, 1987; Bracha et al., 1991; Richards et al., 1991; Welsh, 1992).

\section{Conclusions}

Lesions of the cerebellar cortex or deep nuclei in otherwise normal animals always disrupt conditioned NM responses. Such lesions also disturb unconditioned NM responses by changing the cerebellar regulation of motor systems involved in the execution of this reflex. To what extent there may be learning impairments embedded within these general performance changes cannot be determined with destructive lesions (Welsh and Harvey, 1989b); this question must be answered using other techniques (Welsh and Harvey, 1991). Nonetheless, the cerebellar cortex cannot be considered as the single locus necessary for NM conditioning.

\section{References}

Aitkin LM, Boyd J (1978) Acoustic input to the lateral pontine nuclei. Hearing Res 1:67-77.

Berkley KJ, Hand PJ (1978) Projections to the inferior olive of the cat. II. Comparisons of input from the gracile, cuneate and spinal trigeminal nuclei. J Comp Neurol 180:253-264.

Berthier NE, Moore JW (1990) Activity of deep cerebellar nuclear cells during classical conditioning of nictitating membrane extension in rabbits. Exp Brain Res 83:44-54.

Bracha V, Wu J-Z, Cartwright S, Bloedel JR (1991) Selective involve- 
ment of the spinal trigeminal nucleus in the conditioned nictitating membrane reflex of the rabbit. Brain Res 556:317-320.

Brodal P, Dietrichs E, Walberg F (1986) Do pontocerebellar mossy fibers give off collaterals to the cerebellar nuclei? An experimental study in the cat with implantation of crystalline HRP-WGA. Neurosci Res 4:12-24.

Brooks VB (1986) The neural basis of motor control. New York: Oxford UP.

Chapman CE, Spidalieri G, Lamarre Y (1986) Activity of dentate neurons during arm movements triggered by visual, auditory and somesthetic stimuli in the monkey. J Neurophysiol 55:203-226.

Cody FWJ, Richardson HC (1979) Mossy and climbing fibre mediated responses evoked in the cerebellar cortex of the cat by trigeminal afferent stimulation. J Physiol (Lond) 287:1-14.

Dietrichs E, Bjaalie JG, Brodal P (1983) Do pontocerebellar fibers send collaterals to the cerebellar nuclei? Brain Res 259:127-131.

Dow RS, Morruzzi G (1958) The physiology and pathology of the cerebellum. Minneapolis: University of Minnesota.

Gellman R, Houk JC, Gibson AR (1983) Somatosensory properties of the inferior olive of the cat. J Comp Neurol 215:228-243.

Gormezano I (1966) Classical conditioning. In: Experimental methods and instrumentation in psychology (Sidowski J, ed), pp 385-420. New York: McGraw-Hill.

Guegan M, Horcholle-Bossavit G (1981) Reflex control of the retractor bulbi muscle in the cat. Pfluegers Arch 389:143-148.

Harvey JA (1987) Effects of drugs on associative learning. In: Psychopharmacology, the third generation of progress (Meltzer $\mathrm{H}$, ed), pp 1485-1491. New York: Raven.

Harvey JA, Land T, McMaster SE (1984) Anatomical study of the rabbit's corneal-VIth nerve reflex: connections between cornea, trigeminal sensory complex, and the abducens and accessory abducens nuclei. Brain Res 301:307-321.

Harvey JA, Gormezano I, Cool-Hauser VA (1985) Relationship between heterosynaptic reflex facilitation and acquisition of the nictitating membrane response in control and scopolamine-injected rabbits. I Neurosci 5:596-602.

Holmes GM (1917) The symptoms of acute cerebellar injuries due to gunshot injuries. Brain 40:461-535.

Holstege G, Tan J, van Ham JJ, Graveland GA (1986) Anatomical observations on the afferent projections to the retractor bulbi motoneuronal cell group and other pathways possibly related to the blink reflex in cat. Brain Res 374:321-334.

Huerta MF, Frankfurter A, Harting JK (1983) Studies of the principal sensory and spinal trigeminal nuclei of the rat: projections to the superior colliculus, inferior olive, and cerebellum. J Comp Neurol 220:147-167.

Ito $M$ (1989) Long term depression. Annu Rev Neurosci 12:85-102.

Ito M, Yoshida M, Obata K (1964) Monosynaptic inhibition of the intracerebellar nuclei induced from the cerebellar cortex. Experientia 20:575-576.

Jansen J (1969) On cerebellar evolution and organization from the point of view of a morphologist. In: Neurobiology of cerebellar evolution and development (Llinás R, ed), pp 881-893. Chicago: American Medical Association.

Kelly TM, Zuo CC, Bloedel JR (1990) Classical conditioning of the eye blink reflex in the decerebrate-decerebellate rabbit. Behav Brain Res 38:7-18.

Lavond DG, Steinmetz JE (1989) Acquisition of classical conditioning without cerebellar cortex. Behav Brain Res 33:113-164.

Lavond DG, Steinmetz JE, Yokaitis MH, Thompson RF (1987) Reacquisition of classical conditioning after removal of cerebellar cortex. Exp Brain Res 67:569-593.

Llinás R, Mühlethaler M (1988) Electrophysiology of guinea-pig cerebellar nuclear cells in the in vitro brain stem-cerebellar preparation. J Physiol (Lond) 404:241-258.

Luciani L (1915) The hind-brain. In: Human physiology (Welby F, transl; Holmes GM, ed), pp 419-486. London: Macmillan.

MacKay WA, Murphy JT (1973) Activation of anterior interpositus neurons by forelimb muscle stretch. Brain Res 56:335-339.

MacKay WA, Murphy JT (1974) Responses of interpositus neurons to passive muscle stretch. J Neurophysiol 37:1410-1423.

Matsushita M, Ikeda M (1970) Olivary projections to the cerebellar nuclei in the cat. Exp Brain Res 10:488-500.
McCormick DA, Thompson RF (1984) Cerebellum: essential involvement in the classically conditioned eyelid response. Science 223:296299.

McCormick DA, Lavond DG, Clark GA, Kettner RE, Rising CE, Thompson RF (1981) The engram found? Role of the cerebellum in classical conditioning of the nictitating membrane and eyelid responses. Bull Psychonom Soc 18:103-105.

Miles TS, Wiesendanger M (1975a) Organization of climbing fibre projections to the cerebellar cortex from trigeminal cutaneous afferents and from the SI face area of the cat. J Physiol (Lond) 245:409424.

Miles TS, Wiesendanger M (1975b) Climbing fibre inputs to cerebellar Purkinje cells from trigeminal cutaneous afferents and the SI face area of the cerebral cortex in the cat. J Physiol (Lond) 245:425-445.

Nagao S, Ito M, Karachot L (1984) Site in rabbit flocculus specifically related to eye blinking and neck muscle contraction. Neurosci Res 1:149-152.

Richards WG, Ricciardi TN, Moore JW (1991) Activity of spinal trigeminal pars oralis and adjacent reticular formation units during differential conditioning of the rabbit nictitating membrane response. Behav Brain Res 44:195-204.

Romano AG, Bormann NM, Harvey JA (1991) A unique enhancement of associative learning produced by methylenedioxyamphetamine. Behav Pharmacol 2:225-231.

Shinoda Y, Sugiuchi Y, Futami T, Izawa R (1992) Axon collaterals of mossy fibers from the pontine nucleus in the cerebellar dentate nucleus. J Neurophysiol 67:547-560.

Snider RS, Magoun IIW (1949) Facilitation produced by cerebellar stimulation. J Neurophysiol 12:335-345.

Snider RS, Stowell A (1944) Receiving areas of the tactile, auditory and visual systems in the cerebellum. J Neurophysiol 7:331-357.

Snider RS, McCulloch WS, Magoun HW (1949) A cerebello-bulboreticular pathway for suppression. J Neurophysiol 12:325-334.

Somana R, Kotchabhakdi N, Walberg F (1980) Cerebellar afferents from the trigeminal sensory nuclei in the cat. Exp Brain Res 38:5764.

Steinmetz JE, Lavond DG, Ivkovich D, Logan CG, Thompson RF (1992) Disruption of classical eyelid conditioning after cerebellar lesions: damage to a memory trace system or a simple performance deficit? J Neurosci 12:4403-4426.

Thompson RF (1989) The neurobiology of learning and memory. Science 223:941-947.

Welsh JP (1992) Changes in the motor pattern of learned and unlearned responses following cerebellar lesions: a kinematic analysis of the nictitating membrane reflex. Neuroscience 47:1-19.

Welsh JP, Harvey JA (1989a) Modulation of conditioned and unconditioned reflexes. In: experimental brain research series, 17, The olivocerebellar system in motor control (Strata $P$, ed), pp 374-379. Berlin: Springer.

Welsh JP, Harvey IA (1989b) Cerebellar lesions and the nictitating membrane reflex: performance deficits of the conditioned and unconditioned response. J Neurosci 9:299-311.

Welsh JP, Harvey JA (1991) Pavlovian conditioning in the rabbit during inactivation of the interpositus nucleus. J Physiol (Lond) 444: 459-480.

Welsh JP, Harvey JA (1992) The role of the cerebellum in voluntary and reflexive movements: history and current status. In: The cerebellum revisited (Llinás $\mathrm{R}$, Sotelo $\mathrm{C}$, eds), pp 301-334. Berlin: Springer.

Wilkinson L (1988) systat: the system for statistics. Evanston, IL: Systat, Inc.

Winer BJ (1971) Statistical principles in experimental design. New York: McGraw-Hill.

Yeo $\mathrm{CH}$, Hardiman MJ (1992) Cerebellar cortex and eyeblink conditioning: a reexamination. Exp Brain Res 88:623-638.

Yeo CH, Hardiman MJ, Glickstein M (1985a) Classical conditioning of the nictitating membrane response of the rabbit. II. Lesions of the cerebellar cortex. Exp Brain Res 60:99-113.

Yeo CH, Hardiman MJ, Glickstein M (1985b) Classical conditioning of the nictitating membrane response of the rabbit. III. Connections of cerebellar lobule HVI. Exp Brain Res 60:114-126. 